\title{
Derecho del Consumo
}

Francisca Barrientos Camus

Profesora de Derecho Civil Universidad Diego Portales

Comentario. Aumento de comisión POR MANTENCIÓN DE SERVICIO SIN CONSENTIMIENTO DEL CONSUMIDOR. Cláusulas abusivas, indemnizacioNES Y MULTAS. PRESCRIPCión DE LA ACCIÓN INFRACCIONAL Y RELACIÓN CON LAS DEMÁS ACCIONES. OCTAVA SALA DE la Corte dE Apelaciones DE SANTIAGO, 3 De octubre de 2011, ROL $\mathrm{N}^{\circ}$ 976-2011

Este caso se trata de una demanda colectiva de nulidad de una cláusula abusiva en contra de la empresa proveedora, por el aumento de la comisión por mantención del servicio sin el consentimiento del consumidor.

En los hechos, el año 2006 la empresa Jumbo de Cencosud modificó unilateralmente los contratos de miles de tarjetahabientes de la tarjeta Jumbo Más. Esta modificación tendría efectos sólo para aquéllos que tenían un promedio de compras inferiores a $\$ 50.000$ durante los últimos seis meses incrementado la comisión por mantención de $\$ 460$ a $\$ 990$ mensuales. O sea, se produciría un incremento de $\$ 530$ mensual desde esa fecha en adelante. Para ello, la proveedora invocó la cláusula $16^{\mathrm{a}}$ de los contratos y su reglamento. Esta decisión fue informada por la empresa a través de un pequeño recuadro ubicado en los estados de cuentas de los tarjetahabientes, cuya redacción fue la siguiente:

"informamos que a contar del 1 de febrero de 2006, el valor de la comisión mantención mensual será de \$990”.

Con fecha 16 de noviembre, el SERNAC, trató de llegar a un solución extrajudicial con la empresa que no tuvo éxito. Por este motivo, demandó a Cencosud a través de una acción que protege los intereses colectivos.

La demanda fue notificada el día 12 de enero de 2007. Cencosud se excepcionó de prescripción, en virtud de lo dispuesto en el artículo 24 de la LPDC, lo que fue rechazado en primera instancia y acogido por la Octava Sala de la Corte de Apelaciones de Santiago, con el voto en contra del abogado integrante señor Antonio Barra Rojas.

Aun cuando debo advertir que se esta sentencia no se encuentra firme, hay varios temas que interesa co- 
mentar de este fallo. En primer lugar, las cláusulas abusivas y la nulidad; luego los demás remedios disponibles para el consumidor al amparo de la LPDC; las infracciones y el cómputo de sus plazos y, por último, la relación entre la responsabilidad infraccional (o administrativa) y la responsabilidad civil en la LPDC. Se seguirá este mismo orden.

\section{LAS CLÁUSULAS ABUSIVAS Y LA NULIDAD}

De los hechos del proceso se deduce se cobraba un precio fijo de $\$ 490$ por concepto de mantención mensual de la tarjeta para el titular. Luego, la misma empresa informó a sus clientes el cambio en el costo de la mantención mensual. Para ejercer tal "facultad" tendría que existir una cláusula que lo "autorizara". Si esto es así, no hay duda que se trata de una cláusula abusiva.

Una cláusula que por su redacción permitiera cualquier clase de modificación sin contar con el consentimiento del cliente infringiría lo dispuesto en el artículo 16 letra a) de la LPDC, que califica como abusiva la cláusula que

“otorgue a una de las partes ${ }^{1}$ la facultad de dejar sin efecto o modificar a su solo arbitrio el

${ }^{1}$ Cabe destacar que esta norma hace alusión a las partes (otorguen a una de las partes), lo que es criticable, ya que resulta difícil pensar un caso en que el consumidor imponga una cláusula abusiva en los contratos de adhesión en perjuicio de los derechos del proveedor. contrato o de suspender unila-

teralmente su ejecución".

De los hechos de los procesos, se colige que la empresa Cencosud modificó a su sólo arbitrio el contenido del contrato al aumentar los costos por mantención del servicio.

Asimismo, esta cláusula podría calificarse como abusiva en virtud del artículo 16 letra $\mathrm{g}$ ), que considera las exigencias de la buena fe. Para calificar la abusividad hay que atender "a la finalidad del contrato y las disposiciones especiales que lo rijan". Este examen toma en consideración "parámetros objetivos" de la buena fe, que causen

"perjuicios al consumidor o que generen un desequilibrio importante en los derechos y obligaciones que para las partes se deriven del contrato".

Habría una infracción a las reglas de la buena fe cuando sólo se informa la modificación unilateral del contrato, sin contar con el consentimiento del consumidor (desequilibrio importante en las obligaciones), que sólo rige para ciertos clientes y no para todos (parámetros objetivos) $\mathrm{y}$ que supone un aumento en sus prestaciones (causa perjuicios).

Si una cláusula de un contrato de adhesión es abusiva, el artículo 16 de la Ley dispone que "no producirá efecto alguno". Mauricio Tapia y José M. Valdivia ${ }^{2}$ sostienen que sanción es

${ }^{2}$ Mauricio Tapia Rodríguez y José Miguel Valdivia Olivares, Contrato por adhesión 
la nulidad absoluta, que se integra a las normas del Derecho Común que rigen la materia. Esto es, se siguen las reglas de nulidad del Código Civil, pero tomando en consideración que se trata de una hipótesis de nulidad parcial, pues el contrato de adhesión puede subsistir (artículo 16 A de la LPDC).

De vuelta al fallo que se comenta, la Sala Octava de la Corte de Apelaciones de Santiago revocó la decisión de primera instancia que declaraba nula la cláusula en entredicho. El fundamento para arribar a tal decisión fue que la acción destinada a obtener que se declare abusiva la cláusula 16 del reglamento de uso de la tarjeta Jumbo Más estaba prescrita. Este razonamiento se relaciona con la tercera y cuarta parte de este comentario, que trata la responsabilidad infraccional, sus plazos y la relación con las acciones civiles.

A mi juicio, en este caso la Corte califica de forma errónea el plazo de la acción de nulidad de las cláusulas abusivas. En su concepto, éste se rige por los mismos que la acción infraccional (seis meses). Lo anterior, de alguna forma supone entender que todo el régimen que regula la LPDC sería de naturaleza infraccional, lo que no es así.

Antes de abordar la cuestión infraccional de la LPDC y su relación con los instrumentos civiles haré un repaso a los otros remedios que protegen a los consumidores en caso de aumento unilateral de las comisiones

Ley $N^{0}$ 19.406, Santiago, Editorial Jurídica de Chile, 2002, p. 161 y ss. por parte del proveedor. Ello, con la finalidad de graficar de mejor forma la separación de los estatutos civiles y administrativos; y para mostrar que la LPDC contempla una protección amplia que no se agota sólo en las sanciones infraccionales.

\section{LOS DEMÁS REMEDIOS \\ Y LA INDEMNIZACIÓN}

En la primera parte señalé que el aumento de las comisiones impuestas de forma unilateral por parte del proveedor merecía la calificación de abusiva si estaba contenida en una cláusula del contrato de adhesión, tal como fue el caso. De ahí que se persiga su nulidad, la que se rige por las reglas civiles, por lo tanto, la acción debería prescribir luego de diez años contados desde la celebración del contrato (artículo 1683 del Código Civil), volveré sobre esto en el último punto de este comentario.

Ahora bien, esta cláusula, además de ser abusiva puede ser ilegal. Dicho de otra forma, suele coincidir la abusividad con su ilegalidad. Y cuando eso ocurre se infringen derechos irrenunciables de los consumidores.

Si hay un aumento unilateral de parte del proveedor de las comisiones por mantención del servicio se infringe el derecho irrenunciable de forma anticipada (artículo 4 de la LPDC) a la información veraz y oportuna sobre las condiciones de contratación y los precios (artículo 3 letra $b$ de la LPDC). Me centro en la expresión 'oportunidad', ya que 
lo importante es que la información sobre el aumento de los costos carece de oportunidad necesaria para vincular al consumidor.

Asimismo, podría sostenerse que no se respetó con los términos y condiciones del contrato (artículo 12 de la LPDC) al cambiar unilateralmente las condiciones (costos) de mantención de ciertos clientes.

Incluso, podría pensarse en la discriminación arbitraria si es que la empresa no logra justificar por qué aumentó la comisión sólo a algunos tarjetahabientes y no a todos por igual (artículo 3 letra c de la LPDC).

O bien, desde otra perspectiva si se trata de justificar el consentimiento del cliente, que me parece que en este caso es inexistente, pono constituye aceptación en el ámbito de consumo (artículo 3 letra a de la LPDC).

Entonces, el consumidor cuenta con una de batería de instituciones y remedios de naturaleza civil que lo amparan en la LPDC. Sin perjuicio de la nulidad de la cláusula abusiva, el consumidor, además, puede dirigirse contra el proveedor y pedirle una reparación e indemnización adecuada y oportuna de todos los daños materiales y morales por el incumplimiento (artículo 3 letra e de la LPDC). Indemnización y reparación que tienen la naturaleza civil, por lo tanto está sujeta al régimen de responsabilidad del Derecho Común que será de naturaleza contractual.

Hasta el momento se han analizados sólo las instituciones de naturale-

za civil que se relacionan con el caso expuesto. Ello daría pie para pensar que bastaría la sola interposición de la acción de nulidad o indemnización por parte de los consumidores para dejar sin efecto el aumento de los cobros y lograr una reparación. Sin embargo, hay que tomar en consideración que la acción en defensa de los intereses colectivos la impetró el SERNAC en su calidad de garante de los "intereses generales de los consumidores" (artículo 58 letra g de la LPDC). Como es usual en las causas de consumo, la principal acción interpuesta fue de naturaleza infraccional, además hubo otras acciones civiles como la nulidad, el cese de los cobros ilegales y las restituciones correspondientes.

Con esto, pretendo destacar dos aspectos. Primero, un intento por delimitar los estatutos civiles (nulidad e indemnización) y los administrativos (multas a beneficio fiscal) que contempla esta ley. Y, segundo, recordar que cualquiera puede reclamar en juicio (individual o colectivo) la nulidad de la cláusula abusiva y la indemnización y restitución correspondiente. No se pueden solicitar indemnizaciones por daño moral en los procedimientos colectivos (artículo $51 \mathrm{~N}^{\mathrm{O}} 2$ de la LPDC).

\section{LAS INFRACCIONES Y SUS PLAZOS}

Ya se ha visto la batería de instituciones que amparan al consumidor sólo desde el punto de vista civil de la LPDC. Dentro de esta gama de 
posibilidades no hay que olvidar lo dispuesto en el artículo 23 de la LPDC, una de las más invocadas en las causas de consumo.

Es una norma de carácter infraccional que alcanza a todos los proveedores que participan en la cadena de distribución de los bienes y servicios incluido los fabricantes que, en

"la venta de un bien o en la prestación de un servicio, actuando con negligencia, causa menoscabo al consumidor debido a fallas o deficiencias en la calidad, cantidad, identidad, sustancia, procedencia, seguridad, peso o medida del respectivo bien o servicio"3.

Bajo estas reglas, la responsabilidad del proveedor es administrativa (infraccional) que, a su vez, puede generar un ilícito civil.

En este caso, podría argumentarse que el proveedor (prestador del servicio) cometió una infracción que puede encuadrar dentro del concepto de calidad o procedencia, ocasionándole un perjuicio al consumidor. Para ello se requiere que el proveedor haya actuado con negligencia. Así podría ser condenado a una multa a beneficio fiscal.

El plazo de prescripción de la acción infraccional es de seis meses,

${ }^{3}$ Véase Francisca Barrientos Camus, "La responsabilidad civil del fabricante bajo el artículo 23 de la Ley de Protección de los Derechos de los Consumidores y su relación con la responsabilidad civil del vendedor", en Revista Chilena de Derecho Privado, No 14 , Santiago, julio 2010, pp, 109-158 que se cuenta desde que se haya incurrido en la infracción respectiva. El artículo 26 de la LPDC se refiere a ello, y tal como es posible advertir sólo rige a la acción infraccional. Sin embargo, hay una fuerte tendencia jurisprudencial ${ }^{4}$ que entiende que este plazo también rige a las demás acciones de la LPDC, especialmente a las acciones civiles como serían las de nulidad, las indemnizatorias y restitutorias que se describirá en el punto siguiente.

En este caso, el juez a quo entendió que la infracción se configuraba por los cargos efectuados mes a mes por la empresa proveedora. Para el juez de primera instancia cada cargo extra por la mantención del servicio constituía una infracción en sí misma considerada. De este modo, extendió la prescripción a todas los cobros efectuados por la empresa desde febrero de 2006 hasta enero de 2007 (fecha de notificación de la demanda). Con ello, se evitó acoger la tesis de la prescripción invocada por el demandado.

En segunda instancia se revocó la decisión por estimarse contradictoria. En concepto de la Corte esta solución es contradictoria, porque supone renovación de las infrac-

${ }^{4}$ Sobre este punto, véase el estudio de Juan Ignacio Contardo, que describe la prescripción en el ámbito del consumo, y se refiere a esta tendencia jurisprudencial a modo de crítica, en Juan Ignacio Contardo GonzÁlez, "Prescripción de la acción indemnizatoria en la Ley de Protección al Consumidor: tendencias jurisprudenciales", en Cuadernos de Extensión Jurídica, No 21, Santiago, 2011. 
ciones. La Corte de Apelaciones estimó que la infracción se cometió cuando se informó en las cartolas de los consumidores el aumento de cobro y como había transcurrido más de seis meses de la comunicación efectuada por la empresa, la acción para declarar la nulidad de la cláusula abusiva ya estaba prescrita. En efecto, sentenció:

"[Q]ue, de los antecedentes reunidos en autos, aparece en forma clara y precisa -circunstancia en la que están contestes las partes- que los hechos que fundamenta una de las acciones deducidas, y que constituirían infracciones a la Ley 19.496, fueron realizados por la de-
El tema del cómputo del plazo de prescripción es discutible. Nadie niega que seis meses constituye un breve plazo de prescripción de la acción infraccional, y que por este motivo la jurisprudencia ha ideado una serie de tendencias para ampliarlo. Se ha hablado ${ }^{6}$ del conocimiento del deudor en las causas sobre publicidad engañosa de las carreras de perito forense; de la fecha del contrato en algunos supuestos de publicidad engañosa; en cada cuota devengada que contiene un interés excesivo, entre otras.

En este mismo sentido va el voto de la disidencia de la sentencia comentada que entiende que la inclusión y permanencia de la cláusula abusiva y el cobro ilegal de las comisiones configura un ilícito de carácter permanente. En este sentido, la infracción de la conducta no está compuesta por una sola acción o una única acción, sino por una pluralidad de ellas, que se mantiene en el tiempo en tanto el sujeto persevere en su actividad consumativa, no obstante que el agente pueda en cualquier tiempo cesar en su conducta ${ }^{7}$.

Más allá, me interesa destacar que este de corto tiempo se aplicó también para declarar la prescripción de la acción de nulidad de la cláusula abusiva, lo que a todas luces marzo de 2006, entendiéndose que el cliente acepta si mantiene o utiliza la tarjeta después de 30 días de expedida la comunicación respectiva" 5 .

\footnotetext{
${ }^{5}$ Considerando $6{ }^{\circ}$ Corte de Apelaciones de Santiago.
}

\footnotetext{
${ }^{6}$ Contardo (n. 4).

${ }^{7}$ Para arribar a tal conclusión el abogado integrante se apoya en un informe en Derecho que cita la doctrina de Mario Garrido Montt y Enrique Cury, que distinguen los mencionados delitos de los instantáneos de efectos permanentes.
} 
es criticable. No se entiende porqué la Corte aplicó la misma prescripción para todas las acciones. Esto no tiene fundamento alguno en la LPDC y no es más que una obra de la jurisprudencia de Policía Local, que considera que la LPDC sólo regula sanciones contravencionales. Esto se relaciona con el último punto de este comentario que veré a continuación.

IV. LA RELACIÓN ENTRE

LA RESPONSABILIDAD INFRACCIONAL Y LAS INSTITUCIONES CIVILES DE LA LEY N ${ }^{\circ} 19.496$

A mi juicio, la Corte presupone que todas las instituciones y remedios que dispone el consumidor, examinadas con anterioridad (desde la nulidad hasta la infracción al artículo 23), se rigen por las normas de la responsabilidad infraccional de la LPDC. De otra forma no se explica porqué la Corte acogió la excepción de prescripción interpuesta por la empresa proveedora; $y$, con ello mantuvo los cobros impuestos de forma unilateral. No estoy de acuerdo con esta solución.

En efecto, la Corte de Apelaciones de Santiago sentenció:

“...los hechos que se le imputan a la demanda como constitutivos de infracción a dicha ley se encontraba vencido en exceso, sin que haya existido de por medio ningún hecho o acto jurídico que lo haya suspendido o interrumpido. Así, es forzoso concluir que las acciones intentadas en autos por el Servicio Nacional del Consumidor (SERNAC) y los actores coadyuvantes se encuentran prescritas a la fecha de la demanda, lo que debe ser declarado por este tribunal"8.

Así, revocó la sentencia de primera instancia y declaró que se encontraba prescrita la acción destinada a obtener que se declare que es abusiva la clausula 16 del reglamento de uso de la tarjeta Jumbo Más.

Para reforzar tal decisión esgrimió la tesis de que el plazo de prescripción de la acción se cuenta desde la fecha de celebración del contrato, que en este caso cierra todas las posibilidades de defensa al consumidor. La Corte agregó:

"Además, se debe tener presente que si la demandada hizo uso de la cláusula que se califica como abusiva en enero de 2006, comunicándolo a sus clientes en las boletas de pago de febrero de ese año, se debe necesariamente concluir que fue incorporada en los contratos o reglamentos respectivos con anterioridad a esas datas, lo que abona la conclusión de esta Corte en orden a que las acciones

\footnotetext{
${ }^{8}$ Considerando $12^{\circ}$ Corte de Apelaciones de Santiago.
} 
ejercidas se extinguieron por la prescripción"?.

Incluso, el mismo juez a quo, que acogió la demanda, también adhirió a la posición de la prescripción de seis meses. Por ello tuvo que maquinar una extensión del plazo de prescripción infraccional estimando que cada hecho en sí mismo constituye una nueva infracción y desde esa nueva infracción comienzan a correr los seis meses. En efecto consideró:

“...el plazo de prescripción se renueva cada vez que se realiza a los clientes de la Tarjeta Jumbo Mas un nuevo cobro mensual en virtud del hecho denunciado como infraccional, concluyendo que la prescripción solicitada sólo corresponde declararla en relación a las infracciones derivadas de cobros realizados en forma previa al 12 de julio de $2006 " 10$.

En el fondo, es posible apreciar que hay una confusión de regímenes jurídicos, que se traduce en la falta de claridad respecto del régimen de la acción infraccional (y de la responsabilidad infraccional) con los demás que coexisten en la LPDC. Aquí, se aplica el plazo de los seis meses para todas las acciones sin distinción alguna.

${ }^{9}$ Considerando $12{ }^{\circ}$ Corte de Apelaciones de Santiago.

${ }^{10}$ Considerando $5^{\circ}$ Corte de Apelaciones.
Me parece que el plazo de prescripción de la acción destinada a obtener la nulidad de la cláusula abusiva, al ser una acción civil es -por integración- de diez años contados desde la fecha de celebración del contrato. Otra cosa muy distinta es la sanción infraccional.

Es lamentable que este caso se haya confundido la aplicación de estos estatutos. Aun cuando hay que reconocer que esto es una práctica arraigada en la jurisprudencia del consumo. Ya he dicho en otras partes ${ }^{11}$ que la jurisprudencia mayoritaria ha acuñado la siguiente expresión:

"la responsabilidad civil es una consecuencia inmediata y directa de la responsabilidad infraccional" 12 .

${ }^{11}$ Francisca Barrientos Camus, "La distinción entre la calidad y la seguridad de los productos. Algunos problemas que presenta la responsabilidad del vendedor en las ventas de consumo", en Gonzalo Figueroa Yáñez et alii (coords.), Santiago, Editorial Abeledo Perrot Legal Publishing, 2011, pp. 683-696 y Francisca Barrientos Camus, "Algunas reflexiones sobre el desbordamiento de la responsabilidad infraccional en la Ley $\mathrm{N}^{\circ}$ 19.496", en Revista de Derecho de la Empresa, $\mathrm{N}^{\circ} 25$, Santiago, 2011, pp. 55-80 y Francisca Barrientos Camus, "Un repaso crítico a la historia del sistema de crédito al consumidor regulado en la Ley 19.496", en GacetaJurídica, $\mathrm{N}^{\circ} 372$, Santiago, 2011, pp. 7-15

${ }^{12}$ Para mayor información puede consultarse, Muñoz con Mueblería Peña y Morales, Juzgado de Policía Local de Antofagasta, 26 de agosto de 2008, rol No 5216-2008); Menares con Almacenes París, Juzgado de Policía Local de Antofagasta, 15 de julio de 2008, rol $\mathrm{N}^{\mathrm{O}}$ 3704-2008; Mujica con Castro, Juzgado Policía 
El fundamento de esta tesis se encontraría en los artículos 23 y 24 que establecen la regla general de las infracciones de la LPDC; entonces, todas las disposiciones de la ley que no contengan sanciones deberían ser penadas con infracciones traducidas en multas de hasta 50 UTM. Como sería el caso del plazo de prescripción de la acción de nulidad, que no cuenta con una norma determinada en la LPDC. Asimismo, en virtud de los artículos 9 y 14 de la ley $\mathrm{N}^{\circ} 18.223$, el juez de policía local naturalmente conoce denuncias infraccionales y aplica multas, con lo que no podría conocer causas que contengan sólo aspectos civiles.

Sin embargo, la doctrina distingue estos estatutos. Francisco Fernández Fredes ${ }^{13}$ distingue entre los

Local de Antofagasta, 30 de junio de 2009, rol No 3788.2009. En la línea de la responsabilidad por publicidad engañosa Castillo y otros con Corporación Santo Tomás, Corte de Apelaciones de Temuco, 4 de diciembre de 2008, rol No 9342008, Legal Publishing No 41433); Bevilacqua con Instituto Profesional Santo Tomás, Corte de Apelaciones de Antofagasta, 5 de febrero de 2009, rol No 143-2008, Legal Publishing $\mathrm{N}^{\mathrm{o}}$ 417682. Desde el punto de la vista de la garantía legal, véase Cepeda con Comercial Automotora Prime, Tercer Juzgado de Policía Local de Antofagasta, 26 de octubre de 2008, rol No 7325-2008; Langanbach con Supermercado Jumbo, Segundo Juzgado de Policía Local de Maipú, 17 de julio de 2007, rol No 5265-2006, entre otros. Indirectamente véase Varas con Empresa La Polar, Corte de Apelaciones de La Serena, 8 de agosto de 2007, rol No $144-2007$, Legal Publishing No 36982.

${ }^{13}$ Francisco Fernández, Manual de derecho chileno de protección al consumidor, Santiago, Editorial Lexis Nexis, 2003, pp. 23-33. incumplimientos que generan responsabilidad infraccional (multas) e incumplimientos no infraccionales. José Luis Guerrero ${ }^{14}$ considera que de lege lata debiera distinguirse entre la infracción sin incumplimiento contractual, el incumplimiento contractual sin infracción, y la infracción e incumplimiento contractual (situaciones mixtas). De lege ferenda postula que el órgano competente, atendida la materia indemnizatoria y mercantil de la LPDC debe ser el juez de letras, siguiendo el procedimiento sumario o, bien, uno especial, con comparecencia obligatoria de abogado en caso de superar determinada cuantía, y sin olvidar la incorporación de mecanismos previos de resolución alternativa de conflictos, tales como mediación, conciliación o participación de un tercero experto.

Hernán Corral ${ }^{15}$, a propósito de la garantía legal, va en la misma línea, al distinguir las normas que tipifican y sancionan infracciones, que serían las conductas descritas en los artículos 18, 23, 24 inciso $2^{\circ}, 25$, la norma de clausura del artículo 24 y otra sobre la prescripción del artículo 26; y,

${ }^{14}$ José Luis Guerrero Becar, "La distinción entre contravención infraccional e incumplimiento contractual o contravención civil en materia de protección de derechos del consumidor", en Alejandro GuZMÁn BRIто (edit.), Colección de estudios de Derecho Civil en homenaje a la profesora Inés Pardo de Carvallo, Valparaíso, Ediciones Universitarias de Valparaíso, 2008, pp. 442-453.

${ }^{15}$ Hernán Corral Talciani, "Ley de protección al Consumidor y responsabilidad civil", en Cuadernos de Extensión Jurídica, $\mathrm{N}^{\circ}$ 3, Santiago, 1999, pp. 169-170. 
las normas que establecen derechos opcionales de reposición, imputación o devolución, que serían los casos de los artículos 19 y 20. En igual sentido se pronuncia Enrique Aimone ${ }^{16}$, al estudiar la relación entre la garantía legal y el artículo 23.

Juan Contardo ${ }^{17}$, en el ámbito de agencias de viajes da un argumento de texto que sirve para reforzar la competencia de los juzgados de policía local en el ámbito civil Ricardo Sandoval ${ }^{18}$ aunque, sin decirlo expresamente, también distinguiría entre las responsabilidades infraccionales y las civiles.

En definitiva, se espera una debida comprensión del estatuto de las normas de consumo, a fin de procurar una adecuada defensa del consumidor. En este caso, se debió declarar 274 prescrita la acción infraccional y no las demás acciones civiles.

\section{Bibliografía}

Aimone Gibson, Enrique, Derecho de Protección al consumidor, Santiago, Editorial Jurídica Conosur, 1998.

Barrientos Camus, Francisca, "La responsabilidad civil del fabricante bajo el artículo 23 de la Ley de Protección de los Derechos de los Consumidores

${ }^{16}$ Enrique Aimone Gibson, Derecho de Protección al consumidor, Santiago, Editorial Jurídica Conosur, 1998, p. 94.

${ }^{17}$ Juan Ignacio Contardo González, Responsabilidad civil contractual de las agencias de viajes, Santiago, Editorial Abeledo PerrotLegal Publishing, 2010, pp. 122-125.

${ }^{18}$ Ricardo Sandoval López, Derecho del consumidor, Santiago, Editorial Jurídica de Chile, 2004, pp. 125-139. y su relación con la responsabilidad civil del vendedor", en Revista Chilena de Derecho Privado, No 14, Santiago, julio 2010.

Barrientos Camus, Francisca, "La distinción entre la calidad y la seguridad de los productos. Algunos problemas que presenta la responsabilidad del vendedor en las ventas de consumo", en Gonzalo FigueroA YÁñez et alii ( coords.), Santiago, Editorial Abeledo Perrot Legal Publishing, 2011.

Barrientos Camus, Francisca, "Algunas reflexiones sobre el desbordamiento de la responsabilidad infraccional en la Ley N 19.496", en Revista de Derecho de la Empresa, $\mathrm{N}^{\circ}$ 25, Santiago, 2011.

Barrientos Camus, Francisca, "Un repaso crítico a la historia del sistema de crédito al consumidor regulado en la Ley 19.496", en Gaceta Jurídica, $\mathrm{N}^{\circ}$ 372, Santiago, 2011.

Contardo González, Juan Ignacio, "Prescripción de la acción indemnizatoria en la Ley de Protección al Consumidor: tendencias jurisprudenciales", en Cuadernos de Extensión Jurídica, No 21, Santiago, 2011.

CONTARDO GonzÁlez, Juan Ignacio, Responsabilidad civil contractual de las agencias de viajes, Santiago, Editorial Abeledo Perrot-Legal Publishing, 2010.

Corral Talciani, Hernán, "Ley de protección al Consumidor y responsabilidad civil", en Cuadernos de Extensión Jurídica, No 3 , Santiago, 1999, pp. 169-170.

Fernández, Francisco, Manual de derecho chileno de protección al consumidor, Santiago, Editorial Lexis Nexis, 2003.

Guerrero Becar, José Luis, "La distinción entre contravención infraccio- 
nal e incumplimiento contractual o contravención civil en materia de protección de derechos del consumidor", en Alejandro GUZMÁN BRITO (edit.), Colección de estudios de Derecho Civil en homenaje a la profesora Inés Pardo de Carvallo, Valparaíso, Ediciones Universitarias de Valparaíso, 2008.
Sandoval López, Ricardo, Derecho del consumidor, Santiago, Editorial Jurídica de Chile, 2004.

Tapia Rodríguez, Mauricio y José Miguel Valdivia Olivares, Contrato por adhesión Ley $N^{0}$ 19.406, Santiago, Editorial Jurídica de Chile, 2002. 